\title{
Antiproliferative effect of the Ginkgo biloba extract is associated with the enhancement of cytochrome P450 1B1 expression in estrogen receptor-negative breast cancer cells
}

\author{
XIAO-DAN ZHAO, NI DONG, HONG-TAO MAN, ZHONG-LIN FU, \\ MEI-HONG ZHANG, SHUANG KOU and SHI-LIANG MA \\ College of Bioscience and Biotechnology, Shenyang Agricultural University, Shenyang, Liaoning 110866, P.R. China
}

Received May 23, 2013; Accepted July 09, 2013

DOI: $10.3892 /$ br. 2013.150

\begin{abstract}
Ginkgo biloba is a dioecious tree and its extract is a complex mixture that has been used for thousands of years to treat a variety of ailments in traditional Chinese medicine. The aim of this study was to present our observations on the inhibitory effects of different Ginkgo biloba extracts on human breast cancer cell proliferation and growth. Our results demonstrated that treatment of MCF-7 and MDA-MB-231 human breast cancer cells with Ginkgo biloba leaves and ginkgo fruit extract inhibited cell proliferation. It was also observed that this inhibition was accompanied by the enhancement of cytochrome P450 (CYP) 1B1 expression in MDA-MB-231 cells. In addition, treatment with ginkgo fruit extract resulted in a higher CYP1B1 expression in MDA-MB-231 cells compared to treatment with the Ginkgo biloba leaves extract. Our results suggested that the inhibitory effects of the Ginkgo biloba extract on estrogen receptor-negative breast cancer proliferation and the induction of CYP1B1 expression may be exerted through an alternative pathway, independent of the estrogen receptor or the aryl hydrocarbon receptor pathway.
\end{abstract}

\section{Introduction}

Ginkgo biloba is a dioecious tree and has been used for thousands of years to treat a variety of ailments in traditional Chinese medicine (1). The Ginkgo biloba extract is a complex mixture that mainly contains flavonoids (primarily quercetin, kaempferol and isorhamnetin) and terpene lactones (ginkgolides and bilobalide) (2). Extensive investigation of the main bioactive constituents of the Ginkgo biloba extract revealed several important pharmacological effects. It was previously reported that the Ginkgo biloba extract exerts an antioxidant effect by

Correspondence to: Professor Shi-Liang Ma, College of Bioscience and Biotechnology, Shenyang Agricultural University, 120 Dongling Road, Shenyang, Liaoning 110866, P.R. China

E-mail:msl@syau.edu.cn

Key words: breast cancer, Ginkgo biloba, cytochrome P450 1B1, estrogen receptor scavenging reactive oxygen species (3), reduces platelet aggregation and exhibits neuroprotective properties (4). Previous studies demonstrated the potential benefits of the Ginkgo biloba extract in the treatment of Alzheimer's disease (5), learning and memory deficits (6), cerebrovascular diseases (7), cardiovascular diseases (8), climacteric vasomotor symptoms and postmenopausal syndrome $(9,10)$. It was also demonstrated that the Ginkgo biloba extract possesses antitumor properties (11), may induce cancer cell apoptosis and differentiation and inhibit the progression of human colon cancer (12), hepatocellular carcinoma (13), pancreatic (14) and gastric cancer (15).

Cytochrome P450 (CYP) is a type of heme-thiolate protein that is ubiquitously found in the biosphere. This enzyme family is crucial in several biological processes, such as the oxidative metabolism of exogenous and endogenous organic chemicals, the biological transformation of drugs or xenobiotics, the metabolism of chemical carcinogens and the biosynthesis of physiologically crucial compounds, such as steroids and fatty acids (16). Human CYPs are associated with a number of diseases, such as hypertension, diabetes, obesity and hepatic, infectious and inflammatory diseases $(17,18)$. Members of the CYP family have been identified in healthy and cancerous extrahepatic tissue, such as breast cancer cells, and are associated with tumor development and progression (19-24).

Three types of CYP1 enzymes are expressed in humans, CYP1A1, CYP1A2 and CYP1B1. The members of this family are under the transcriptional regulation of the aryl hydrocarbon receptor (AhR) and are known to activate pro-carcinogens, such as polycyclic aromatic hydrocarbons (PAHs) (25). All the members of this family are expressed in extrahepatic tissues. However, CYP1B1 is uniquely overexpressed in a wide range of human cancers of different histogenetic types compared to normal tissues (26-28). Several studies reported that the Ginkgo biloba extract exhibits differential induction of CYPs (29-31). The aim of this study was to assess whether the Ginkgo biloba extract induces CYP1B1 expression and affects the proliferation of MCF-7 and MDA-MB-231 human breast cancer cells.

\section{Materials and methods}

Ginkgo biloba and Ginkgo biloba extract. The Ginkgo biloba leaves and ginkgo fruit were obtained from the Shenyang 
Agricultural University, without prior exposure to chemical pesticides. This study was conducted in accordance with the University's ethic regulations concerning the use of human related materials in scientific research and with the approval of the ethics committtee of Shenyang Agricultural University.

High-quality Ginkgo biloba leaves and ginkgo fruit were used for the preparation of an aqueous extract. Ginkgo biloba leaves and ginkgo fruit $(50 \mathrm{~g})$ were cut and minced separately and $100 \mathrm{ml}$ cold water was added to suspend the minced Ginkgo biloba mixture. The mixture was maintained at $80^{\circ} \mathrm{C}$ for $40 \mathrm{~min}$ and was then subjected to negative pressure filtration, followed by the addition of distilled water to the clear supernatant to a final volume of $100 \mathrm{ml}$. The supernatant was then filtered through a $0.45-\mu \mathrm{m}$ membrane filter into a sterile collection bottle and was kept at $2-8^{\circ} \mathrm{C}$ in a refrigerator as a final extract for subsequent experimental use.

Cell lines and cell culture. The MCF-7 and MDA-MB-231 human breast cancer cell lines were purchased from the cell bank of the Chinese Academy of Sciences. MCF-7 and MDA-MB-231 cells were removed from the liquid nitrogen and preheated for $1 \mathrm{~min}$ at $37^{\circ} \mathrm{C}$. The cells were then transferred to a $25-\mathrm{cm}^{2}$ cell culture vessel, followed by the addition of 10-15 ml RPMI-1640 cell culture medium (Hyclone, Logan, UT, USA) supplemented with $10 \%$ fetal bovine serum (FBS) and $1 \%$ antibiotics. The cells were then cultured at $37^{\circ} \mathrm{C}$ in an atmosphere of $5 \% \mathrm{CO}_{2}$ in a tissue culture apparatus. The cell culture medium was changed after culture for $12 \mathrm{~h}$. After growing to $80-90 \%$ confluency, the cells were harvested and reseeded for the treatment assay.

Experimental treatments. For the Ginkgo biloba extract treatment assay, MCF-7 and MDA-MB-231 cells were divided into three treatment groups: the control group, the Ginkgo biloba leaves extract group and the ginkgo fruit extract group. Cells (1-1.5 $\times 10^{6}$ MCF-7 or $4-5 \times 10^{6}$ MDA-MD-231) were plated in $10-15 \mathrm{ml}$ of RPMI-1640 cell culture medium supplemented with $10 \%$ FBS and $1 \%$ antibiotics. The MCF-7 cells were then incubated with $500 \mu \mathrm{l}$ extract of Ginkgo biloba leaves as the first group and $500 \mu 1$ extract of ginkgo fruit as the second group. Cells without the addition of Ginkgo biloba extract served as the control group. MDA-MB-231 cells were treated with Ginkgo biloba extract at the same dose as MCF-7 cells. Cell morphology was observed after $48 \mathrm{~h}$ under a confocal laser scanning microscope. The cells of each group were then collected and counted and RNA was extracted.

Qualitative reverse transcription-polymerase chain reaction (RT-PCR). Total RNA was extracted using TRIzol reagent (Invitrogen Life Technologies, Carlsbad, CA, USA) and the first-strand complementary DNA (cDNA) was synthesized according to the manufacturer's instructions, using $1 \mu \mathrm{g}$ total RNA with a random primer and the Moloney murine leukemia virus reverse transcriptase, RNase $\mathrm{H}$ minus [M-MLV RTase (RNase $\left.\mathrm{H}^{-}\right)$] (GeneCopoeia, Inc., Rockville, MD, USA). The first-strand cDNA was stored at $-20^{\circ} \mathrm{C}$ for later use.

The PCR primers for CYP1B1 and glyceraldehyde 3-phosphate dehydrogenase (GAPDH) were intron-spanning primer sequences of CYP1B1 and GAPDH and were as follows:
CYP1B1: sense, 5'-GGCTGGATTTGGAGAACGTA-3' and antisense, 5'-GTTGATGAGGCCATCCTTGT-3'; GAPDH: sense, 5'-GGATTTGGTCGTATTGGG-3' and antisense, 5'-GGAAGATGGTGATGGGATT-3'. The size of the PCR products was 419 and $205 \mathrm{bp}$, respectively.

The PCR reactions were performed on a Bio-Rad S1000 thermal cycler (Bio-Rad Laboratories, Inc., Hercules, CA, USA). The PCR amplification was performed in a total reaction volume of $25 \mu \mathrm{l}$, containing $1 \mu \mathrm{l}$ of cDNA sample, $10 \mathrm{pM}$ of each primer, $2.5 \mathrm{mM}$ of deoxyribonucleotide, 10X EasyTaq buffer and 5 units of EasyTaq DNA polymerase (TransGen Biotech, Beijing, China). The cycling parameters were: initial denaturation at $95^{\circ} \mathrm{C}$ for $3 \mathrm{~min}$, followed by 27 cycles of denaturation at $95^{\circ} \mathrm{C}$ for $30 \mathrm{sec}$, annealing at $56^{\circ} \mathrm{C}$ for $30 \mathrm{sec}$ and a final extension at $72^{\circ} \mathrm{C}$ for $30 \mathrm{sec}$. The PCR products were analyzed on $1.2 \%(\mathrm{w} / \mathrm{v})$ agarose gels containing $0.5 \mu \mathrm{g} / \mathrm{ml}$ ethidium bromide and were visualized under UV light.

Quantitative PCR ( $q P C R$ ). qPCR was performed to detect CYP1B1 gene expression. The $20-\mu 1$ reaction mixture contained $4.6 \mu \mathrm{l}$ diethylpyrocarbonate- $\mathrm{H}_{2} \mathrm{O}, 1.0 \mu \mathrm{l}$ cDNA, $2.0 \mu \mathrm{l}(10 \mu \mathrm{M})$ of each primer, $10 \mu \mathrm{l} 2 \mathrm{X}$ All-in-One qPCR Mix and $0.4 \mu 1$ 50X ROX Reference Dye (GeneCopoeia). The thermal cycle program for PCR was as follows: an initial step at $94^{\circ} \mathrm{C}$ for $10 \mathrm{~min}$, followed by 40 cycles of PCR at $94^{\circ} \mathrm{C}$ for $10 \mathrm{sec}$, at $56^{\circ} \mathrm{C}$ for $20 \mathrm{sec}$ and at $72^{\circ} \mathrm{C}$ for $20 \mathrm{sec}$. The fluorescence signal was digitally collected after each cycle of $72^{\circ} \mathrm{C}$ for $20 \mathrm{sec}$. Following PCR amplification, the samples were subjected to a temperature ramp with continuous fluorescence monitoring for melting curve analysis. LightCycler 480 analysis software (Roche Light Cycler 480, Hoffmann-La Roche, Ltd., Basel, Switzerland) was used to obtain the Ct values. The $2^{-\Delta \Delta C t}$ method (32) was used to analyze the relative expression of CYP1B1 in MCF-7 or MDA-MB-231 cells treated with Ginkgo biloba leaves extract or ginkgo fruit extract.

\section{Results}

Effect of Ginkgo biloba extract on cell growth. The cells were collected and counted after treatment for $48 \mathrm{~h}$. The number of MCF-7 cells in the control, first and second groups was $4.2 \times 10^{6}, 3.3 \times 10^{6}$ and $2.6 \times 10^{6}$, respectively. The number of MDA-MB-231 cells in the control, first and second groups was $1.3 \times 10^{7}, 0.9 \times 10^{7}$ and $0.6 \times 10^{7}$, respectively. The cell numbers in the control groups were distinctly higher compared to those in the treatment groups; in addition, the cell numbers in the Ginkgo biloba leaves extract-treated group were significantly higher compared to the ginkgo fruit extract-treated group. These results indicated that treatment with Ginkgo biloba extract significantly inhibited breast cancer cell proliferation and the ginkgo fruit extract exerted a more potent inhibitory effect compared to the Ginkgo biloba leaves extract (Fig. 1).

The cell morphology in the Ginkgo biloba extract and the control group were further examined under a confocal laser scanning microscope after treatment for $48 \mathrm{~h}$. As shown in Fig. 1, in the Ginkgo biloba leaves extract-treated group and the ginkgo fruit extract-treated group, the cells were prone to grow in clusters compared to the cells in the control group. Moreover, the ginkgo fruit extract group exhibited more extensive cell morphology changes compared to the Ginkgo biloba 


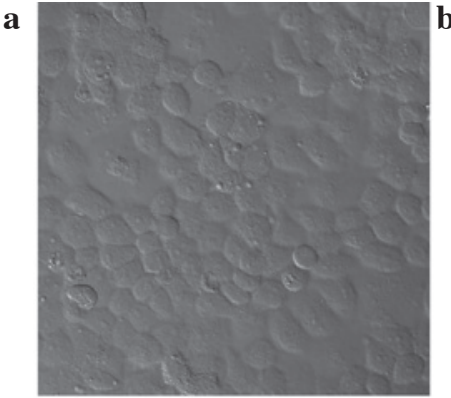

B

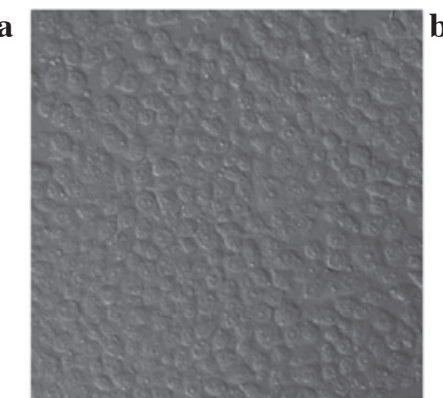

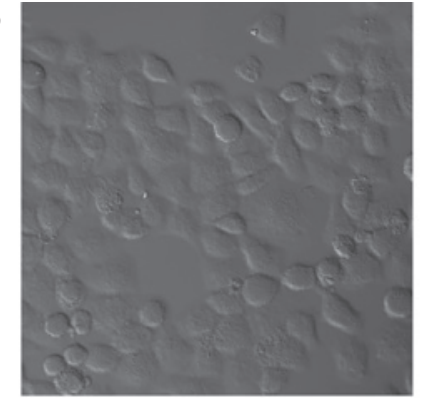
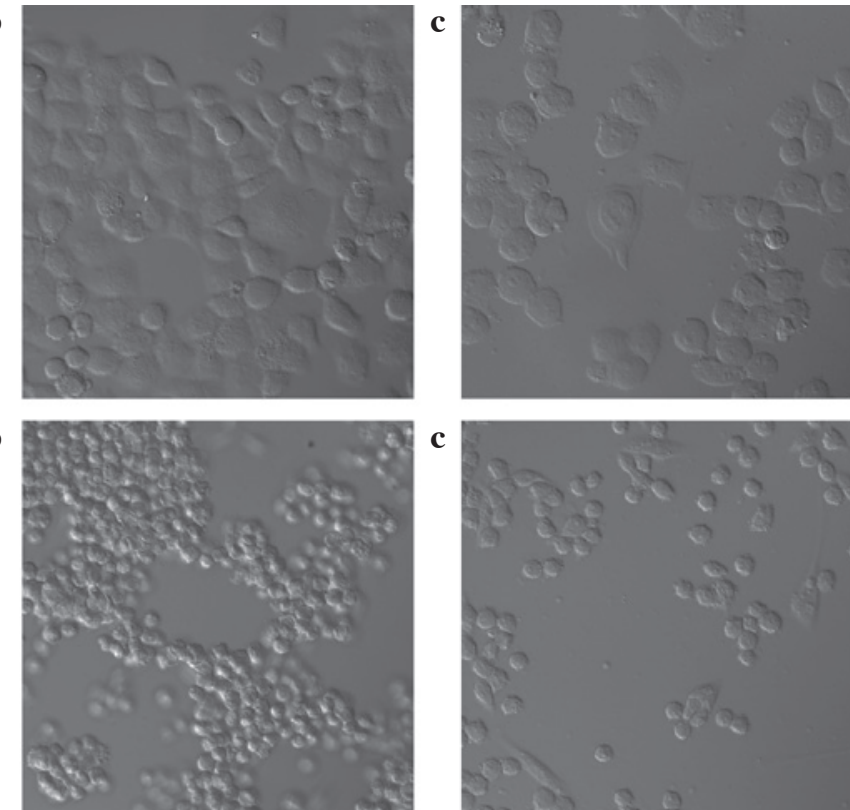

Figure 1. Cell morphology changes in MCF-7 and MDA-MB-231 human breast cancer cell lines treated with the Ginkgo biloba extract. (A) Morphological changes in MCF-7 human breast cancer cells: a, control group; b, Ginkgo biloba leaves extract-treated group; c, ginkgo fruit extract-treated group. (B) Morphological changes in MDA-MB-231 human breast cancer cells: a, control group; b, Ginkgo biloba leaves extract-treated group; c, ginkgo fruit extract-treated group.

A

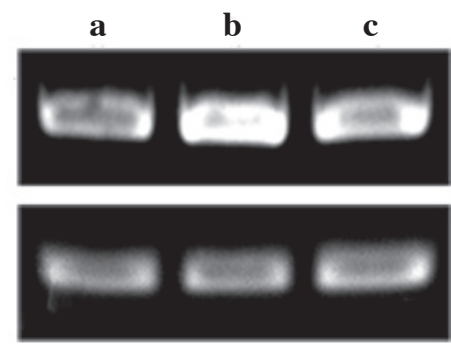

B

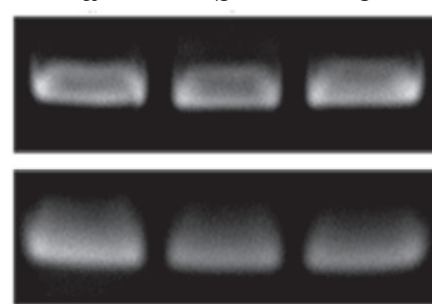

CYP1B1

\section{GAPDH}

Figure 2. Expression of CYP1B1 in (A) MCF-7 and (B) MDA-MB-231 human breast cancer cell lines treated with the Ginkgo biloba extract. The expression of CYP1B1 was analyzed by semi-quantitative reverse transcription-polymerase chain reaction. The GAPDH mRNA was amplified and used as a control. Lanes a and d, control group; b and e, Ginkgo biloba leaves extract-treated group; c and f, ginkgo fruit extract-treated group.

leaves extract group, further indicating the more potent growth inhibitory effect of ginkgo fruit extract treatment compared to the Ginkgo biloba leaves extract treatment.

Induction of CYPIB1 expression in human breast cancer cells treated with Ginkgo biloba extract. The gene expression of CYP1B1 was first confirmed by RT-PCR amplification of the CYP1B1 cDNA (Fig. 2). To ascertain the mechanisms of the inhibition effect of Ginkgo biloba extract on breast cancer cell proliferation and growth, the CYP1B1 gene expression was analyzed by qPCR. As shown in Fig. 3, the CYP1B1 expression in the Ginkgo biloba leaves extract- and ginkgo fruit extract-treated MDA-MB-231 and MCF-7 cells was upregulated. In MCF-7 cells, the CYP1B1 expression was 1.5- and 1.1-fold higher in the ginkgo fruit extract- and in the Ginkgo biloba leaves extract-treated group, respectively, compared to that in the control group. However, in MDA-MB-231 cells, CYP1B1 expression was markedly enhanced, being 7.2- and 2.0-fold higher in the ginkgo fruit extract- and in the Ginkgo biloba leaves extract-treated group, respectively, compared to that in the control group.

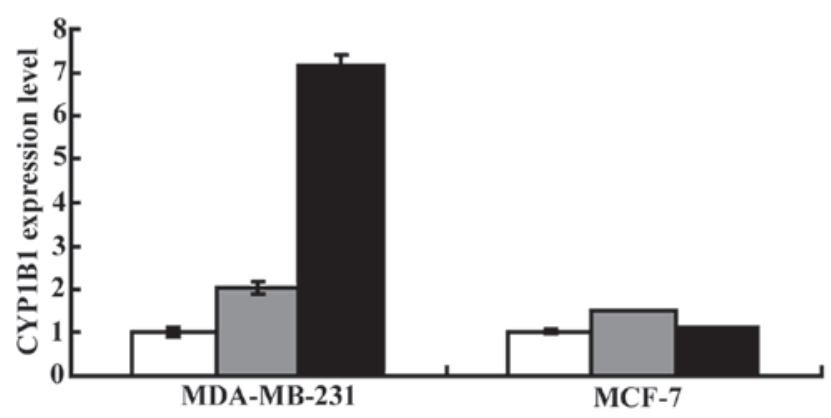

Figure 3. Quantitative polymerase chain reaction analysis of the expression of CYP1B1 at the mRNA level in MCF-7 and MDA-MB-231 cells treated with the Ginkgo biloba extract. White columns, expression of CYP1B1 in the control group; grey columns, expression of CYP1B1 in the Ginkgo biloba leaves extract-treated group; and black columns, expression of CYP1B1 in the ginkgo fruit extract-treated group.

Collectively, these results demonstrated that treatment with the Ginkgo biloba extract enhanced CYP1B1 expression in MDA-MB-231 and MCF-7 cells. The results also demonstrated that MDA-MB-231 cells were more sensitive 
to Ginkgo biloba extract treatment compared to MCF-7 cells. Moreover, the ginkgo fruit extract treatment resulted in a significantly higher induction of CYP1B1 expression compared to the Ginkgo biloba leaves extract, demonstrating the difference in the induction potential of the two different types of Ginkgo biloba extracts.

\section{Discussion}

In this study, we investigated the treatment effects of the Ginkgo biloba leaves extract and ginkgo fruit extract on breast cancer cell proliferation, cell morphology changes and gene expression of CYP1B1. Our results demonstrated that the treatment of MDA-MB-231 human breast cancer cells with either Ginkgo biloba leaves extract or ginkgo fruit extract significantly enhanced CYP1B1 gene expression. Moreover, treatment with ginkgo fruit extract resulted in a more significant enhancement of CYP1B1 gene expression in MDA-MB-231 cells. However, the treatment of MCF-7 cells with either Ginkgo biloba leaves extract or ginkgo fruit extract did not result in a significant enhancement of CYP1B1 gene expression. Taken together, these results indicate that the ginkgo fruit extract was the most effective inducer of CYP1B1 gene expression in human MDA-MB-231 cells. In addition, MDA-MB-231 cell proliferation was also greatly decreased following treatment with Ginkgo biloba leaves extract or ginkgo fruit extract and the greatest decrease was observed in the ginkgo fruit extract treatment group, in parallel with the CYP1B1 gene expression changes.

CYP1B1 is an inducible enzyme regulated through the $\mathrm{AhR}$ (33) and is activated by PAHs and dioxin-like compounds (34). CYP1B1 is regulated by several transcription factors, including the AhR/AhR nuclear translocator complex (Ahr/ARNT), the Sp1 transcription factor, the cyclic AMP (cAMP)-response element-binding protein (CREB) and the estrogen receptor (ER). An estrogen-responsive element that is located in close proximity to the Sp1 transcription factor binding site was recently shown to be involved in the ER $\alpha$ regulation of CYP1B1 expression (35). Estrogen is required for the enhanced $\mathrm{AhR}$ expression and constitutive induction of CYP1B1 expression in MCF-7 cells (36), indicating the possible involvement of estrogen in the induced expression of CYP1B1 in breast tumor cells and the correlation of CYP1B1 expression with the ER $\alpha$ status (37). In ER-negative breast cancer cells, the presence of estrogen was not able to stimulate the expression of CYP1B1 (35), indicating the dependence of CYP1B1 expression on ER. In addition, tamoxifen treatment upregulated the expression of CYP1B1 in breast cancer cells, suggesting that the induction of CYP1B1 expression may reduce the treatment effects of tamoxifen (38). However, in some cells, the expression of CYP1B1 does not depend on estrogen (39), suggesting that CYP1B1 expression may be independent of estrogen and ER, although it may be induced through alternative pathways. 7,12-Dimethylbenz(a)anthracene-induced carcinogenesis is an extensively investigated model of PAH-induced mouse carcinogenesis and a recent study demonstrated that CYP1B1 knockout mice exhibited resistance to 7,12-dimethylbenz(a)anthracene-induced carcinogenesis (40), demonstrating the metabolic effects of CYP1B1. The results of those studies indicated that the regulation of CYP1B1 expression is complex, involving transcription factors, ER and AhR.

According to a previous study, treatment of MDA-MB-231 or MCF-7 breast cancer cells with 2,3,7,8-tetrachlorodibenzo-p-dioxin (TCDD) inhibited cell growth, accompanied by enhanced expression of CYP1B1 by 8-fold in MCF-7 and 30-fold in MDA-MB-231 cells (41). It was previously demonstrated that in MCF-7 cells, the DNA synthesis was significantly suppressed following treatment with TCDD, suggesting an AhR-independent pathway of TCDD-induced antiproliferation in breast cancer cells (42). Moreover, Larsen et al (43) observed that TCDD induced the expression of CYP1B1 mRNA in ER-negative primary human breast epithelial cells, suggesting an alternative pathway of TCDD-induced CYP expression in human breast cancer cells instead of the ER-dependent one. Larsen et al (43) also demonstrated that in ER-positive and ER-negative breast cancer cells, CYP1B1 was expressed constitutively and was induced by TCDD (44). Results of the present study have shown that in ER-negative breast cancer cells, the inhibitory effects of Ginkgo biloba extract on MDA-MB-231 cell proliferation were correlated with CYP1B1 expression induction, which may occur through an ER and AhR-independent pathway. However, the underlying mechanisms require elucidation through further investigations.

\section{Acknowledgements}

This study was funded by the 'Financial support for selected researchers back from abroad (2011)' project of the Liaoning Province.

\section{References}

1. McKenna DJ, Jones K and Hughes K: Efficacy, safety, and use of Ginkgo biloba in clinical and preclinical applications. Altern Ther Health Med 7: 70-86, 88-90, 2001.

2. No authors listed: EGb 761: Ginkgo biloba extract, Ginkor. Drugs R D 4: 188-193, 2003.

3. Brunetti L, Orlando G, Menghini L, Ferrante C, Chiavaroli A and Vacca M: Ginkgo biloba leaf extract reverses amyloid beta-peptide-induced isoprostane production in rat brain in vitro. Planta Med 72: 1296-1299, 2006.

4. Maclennan KM, Darlington CL and Smith PF: The CNS effects of Ginkgo biloba extracts and ginkgolide B. Prog Neurobiol 67: 235-257, 2002.

5. Yao ZX, Han Z, Drieu K and Papadopoulos V: Ginkgo biloba extract (Egb 761) inhibits $\beta$-amyloid production by lowering free cholesterol levels. J Nutr Biochem 15: 749-756, 2004.

6. Gong QH, Wu Q, Huang XN, Sun AS, Nie J and Shi JS: Protective effect of Ginkgo biloba leaf extract on learning and memory deficit induced by aluminum in model rats. Chin J Integr Med 12: 37-41, 2006.

7. Hrehorovska M, Burda J, Domorakova I and Mechirova E: Effect of Tanakan on postischemic activity of protein synthesis machinery in the rat brain. Gen Physiol Biophys 23: 457-465, 2004.

8. Koltermann A, Hartkorn A, Koch E, Furst R, Vollmar AM and Zahler S: Ginkgo biloba extract EGb 761 increases endothelial nitric oxide production in vitro and in vivo. Cell Mol Life Sci 64: $1715-1722,2007$.

9. Oh SM and Chung KH: Estrogenic activities of Ginkgo biloba extracts. Life Sci 74: 1325-1335, 2004.

10. Oh SM and Chung KH: Antiestrogenic activities of Ginkgo biloba extracts. J Steroid Biochem Mol Biol 100: 167-176, 2006.

11. Feng $X$, Zhang $\mathrm{L}$ and Zhu H: Comparative anticancer and antioxidant activities of different ingredients of Ginkgo biloba extract (EGb 761). Planta Med 75: 792-796, 2009. 
12. Chen XH, Miao YX, Wang XJ, et al: Effects of Ginkgo biloba extract EGb761 on human colon adenocarcinoma cells. Cell Physiol Biochem 27: 227-232, 2011.

13. Chao JC and Chu CC: Effects of Ginkgo biloba extract on cell proliferation and cytotoxicity in human hepatocellular carcinoma cells. World J Gastroenterol 10: 37-41, 2004.

14. Zhang Y, Chen AY, Li M, Chen C and Yao Q: Ginkgo biloba extract kaempferol inhibits cell proliferation and induces apoptosis in pancreatic cancer cells. J Surg Res 148: 17-23, 2008.

15. Xu AH, Chen HS, Sun BC, et al: Therapeutic mechanism of Ginkgo biloba exocarp polysaccharides on gastric cancer. World J Gastroenterol 9: 2424-2427, 2003.

16. Bernhardt R: Cytochromes P450 as versatile biocatalysts. J Biotechnol 124: 128-145, 2006.

17. Mao P, Qiao DJ and Ma XR: Cytochrome P450 and iatrology. Chin J Antibiot 36: 93-101, 2011.

18. Orellana M and Guajardo V: Cytochrome P450 activity and its alteration in different diseases. Rev Med Chil 132: 85-94, 2004 (In Spanish).

19. Oyama T, Kagawa N, Kunugita N, et al: Expression of cytochrome P450 in tumor tissues and its association with cancer development. Front Biosci 9: 1967-1976, 2004.

20. Murray GI, Weaver RJ, Paterson PJ, Ewen SW, Melvin WT and Burke MD: Expression of xenobiotic metabolizing enzymes in breast cancer. J Pathol 169: 347-353, 1993.

21. Mace K, Bowman ED, Vautravers P, Shields PG, Harris CC and Pfeifer AM: Characterisation of xenobiotic-metabolising enzyme expression in human bronchial mucosa and peripheral lung tissues. Eur J Cancer 34: 914-920, 1998.

22. Murray GI, McFadyen MC, Mitchell RT, Cheung YL, Kerr AC and Melvin WT: Cytochrome P450 CYP3A in human renal cell cancer. Br J Cancer 79: 1836-1842, 1999.

23. Murray GI: The role of cytochrome P450 in tumour development and progression and its potential in therapy. J Pathol 192: 419-426, 2000.

24. Hashizume T, Imaoka S, Mise M, et al: Involvement of CYP2J2 and CYP4F12 in the metabolism of ebastine in human intestinal microsomes. J Pharmacol Exp Ther 300: 298-304, 2002.

25. Bruno RD and Njar VC: Targeting cytochrome P450 enzymes: a new approach in anti-cancer drug development. Bioorg Med Chem 15: 5047-5060, 2007.

26. Murray GI, Taylor MC, McFadyen MC, et al: Tumor-specific expression of cytochrome P450 CYP1B1. Cancer Res 57: 3026-3031, 1997

27. Gibson P, Gill JH, Khan PA, et al: Cytochrome P450 1B1 (CYP1B1) is overexpressed in human colon adenocarcinomas relative to normal colon: implications for drug development. Mol Cancer Ther 2: 527-534, 2003.

28. Tokizane T, Shiina H, Igawa M, et al: Cytochrome P450 1B1 is overexpressed and regulated by hypomethylation in prostate cancer. Clin Cancer Res 11: 5793-5801, 2005.

29. Deng Y, Bi HC, Zhao LZ, et al: Induction of cytochrome P450s by terpene trilactones and flavonoids of the Ginkgo biloba extract EGb 761 in rats. Xenobiotica 38: 465-481, 2008.

30. He N, Cai HB, Xie HG, Collins X, Edeki TI and Strom SC: Induction of cyp3a in primary cultures of human hepatocytes by ginkgolides $\mathrm{A}$ and $\mathrm{B}$. Clin Exp Pharmacol Physiol 34: 632-635, 2007
31. Li L, Stanton JD, Tolson AH, Luo Y and Wang H: Bioactive terpenoids and flavonoids from Ginkgo biloba extract induce the expression of hepatic drug-metabolizing enzymes through pregnane $X$ receptor, constitutive androstane receptor, and aryl hydrocarbon receptor-mediated pathways. Pharm Res 26 : $872-882,2009$

32. Livak KJ and Schmittgen TD: Analysis of relative gene expression data using real-time quantitative PCR and the $2^{-\Delta \Delta C T}$ method. Methods 25: 402-408, 2001

33. Bhattacharyya KK, Brake PB, Eltom SE, Otto SA and Jefcoate CR: Identification of a rat adrenal cytochrome P450 active in polycyclic hydrocarbon metabolism as rat CYP1B1. Demonstration of a unique tissue-specific pattern of hormonal and aryl hydrocarbon receptor-linked regulation. J Biol Chem 270: 11595-11602, 1995.

34. Shimada T, Oda Y, Gillam EM, Guengerich FP and Inoue K: Metabolic activation of polycyclic aromatic hydrocarbons and other procarcinogens by cytochromes P450 1A1 and P450 1B1 allelic variants and other human cytochromes P450 in Salmonella typhimurium NM2009. Drug Metab Dispos 29: 1176-1182, 2001.

35. Tsuchiya Y, Nakajima M, Kyo S, Kanaya T, Inoue M and Yokoi T: Human CYP1B1 is regulated by estradiol via estrogen receptor. Cancer Res 64: 3119-3125, 2004.

36. Spink DC, Katz BH, Hussain MM, Pentecost BT, Cao Z and Spink BC: Estrogen regulates Ah responsiveness in MCF-7 breast cancer cells. Carcinogenesis 24: 1941-1950, 2003.

37. Sasaki M, Tanaka Y, Kaneuchi M, Sakuragi N and Dahiya R: CYP1B1 gene polymorphisms have higher risk for endometrial cancer, and positive correlations with estrogen receptor $\alpha$ and estrogen receptor $\beta$ expressions. Cancer Res 63: 3913-3918, 2003.

38. Brockdorff BL, Skouv J, Reiter BE and Lykkesfeldt AE: Increased expression of cytochrome p450 1A1 and 1B1 genes in anti-estrogen-resistant human breast cancer cell lines. Int J Cancer 88: 902-906, 2000.

39. Berge G, Mollerup S, Øvrebø S, et al: Role of estrogen receptor in regulation of polycyclic aromatic hydrocarbon metabolic activation in lung. Lung Cancer 45: 289-297, 2004.

40. Buters JT, Sakai S, Richter T, et al: Cytochrome P450 CYP1B1 determines susceptibility to 7,12-dimethylbenz[a] anthracene-induced lymphomas. Proc Natl Acad Sci USA 96 1977-1982, 1999

41. Dohr O, Vogel C and Abel J: Different response of 2,3,7,8-tetrachlorodibenzo-p-dioxin (TCDD)-sensitive genes in human breast cancer MCF-7 and MDA-MB 231 cells. Arch Biochem Biophys 321: 405-412, 1995.

42. Yoshioka H, Hiromori Y, Aoki A, et al: Possible aryl hydrocarbon receptor-independent pathway of 2,3,7,8-tetrachlorodibenzo-p-dioxin-induced antiproliferative response in human breast cancer cells. Toxicol Lett 211: 257-265, 2012.

43. Larsen MC, Angus WG, Brake PB, Eltom SE, Sukow KA and Jefcoate CR: Characterization of CYP1B1 and CYP1A1 expression in human mammary epithelial cells: role of the aryl hydrocarbon receptor in polycyclic aromatic hydrocarbon metabolism. Cancer Res 58: 2366-2374, 1998.

44. Angus WG, Larsen MC and Jefcoate CR: Expression of CYP1A1 and CYP1B1 depends on cell-specific factors in human breast cancer cell lines: role of estrogen receptor status. Carcinogenesis 20: 947-955, 1999. 